\section{Crece la conciencia del malestar mundial en Davos}

Francisco J. Ibisate*

Departamento de Economía Universidad Centroamericana "José Simeón Cañas"

pp. 108-113
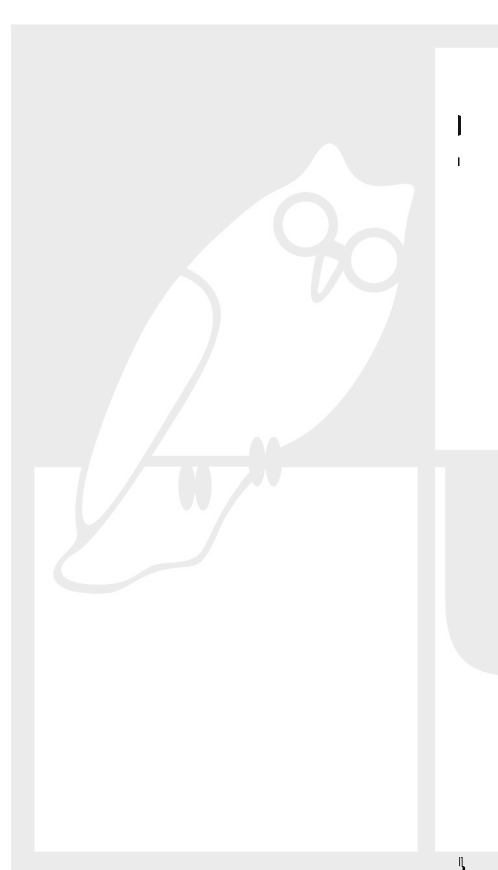

- Catedrático e investigador del Departamento de Economia de la UCA. Dirección electrónica: ibisate@buho.uca.edu.sv

\section{No hace falta un documento final}

El foro económico mundial de Davos, desde su primera reunión en 1970, no publica ningún documento final sobre objetivos y politicas económicas recomendadas por los más de 2300 asistentes, entre empresarios, jefes de Estado y expertos. En los últimos años, se ha hecho costumbre que sus organizadores encomienden a una empresa, en este caso la Gallup, realizar una encuesta a 50 mil personas de 60 países. Al mismo tiempo que los grandes empresarios otean el horizonte económico, la encuesta recoge un abanico de problemas mundiales. El titular de LaNacion.COM, publicado una semana antes del foro, "Crece el optimismo mundial respecto del futuro económico", es curioso. Cabe agregar que, a medida que el foro avanzó, se percibió cómo ese optimismo mundial se eclipsó.

El 43 por ciento de los consultados en 2005 creía que el futuro sería más próspero. Solo una de cada tres personas consultadas consideró que el mundo será un lugar menos seguro para las generaciones futuras. Los entrevistados en Oriente Medio, África y Asia, sobre todo en China, se mostraron más optimistas sobre las perspectivas económicas globales, mientras que en Europa y Estados Unidos había menos entusiasmo. También se hacen fuertes críticas a políticos y empresarios. Las cuatro principales características que, en general, se atribuyen a los políticos son muy negativas: deshonestos (61 por ciento), responden a presiones (53 por ciento), tienen demasiado poder (53 por ciento) y carecen de ética (49 por ciento). El 46 por ciento cree que los empresarios tienen demasiado poder. Las principales prioridades que deberían tener los líderes, en 2006, son el crecimiento económico (17 por ciento), reducir la brecha entre ricos y pobres (16 por ciento), proteger el medio ambiente (14 por ciento) y eliminar la 
pobreza (12 por ciento). La guerra contra el terrorismo se encuentra en quinto lugar (LaNación.COM, 17 de enero de 2006).

No todos los congregados participaron del mismo optimismo económico, para lo cual tenian sobradas razones. En septiembre de 2005, con ocasión de celebrarse los 60 años de Naciones Unidas, los delegados de los 191 países no mostraron mayor interés por actualizar los Objetivos del milenio ni los relacionados con la paz, la seguridad y el desarme, ni los relacionados con la equidad y la justicia económicas. En los meses de noviembre y diciembre, primero en Mar del Plata, el fiasco del tratado de libre comercio de América Latina, y luego, en la OMC de Hong Kong, el incumplimiento de las promesas pactadas y relegadas a la siguiente década por los países industrializados. La teoría del libre comercio pierde credibilidad. En consecuencia, el último día de Davos, el foro quiso reactivar el programa de Doha (Qatar). A finales de 2005 y comienzos de 2006, la crisis política del Próximo y Medio Oriente se agudizó. Las potencias ocupantes desearian retirarse decorosamente de Irak, mientras que Bush y Rice contribuyen a que el nuevo gobierno de Irán se decida por ir más allá de la electricidad nuclear, y el grupo palestino Hámas, democráticamente elegido, le devuelve a Israel el mismo trato que este le ofreció durante largos años. La economía, la seguridad, el desarme y la paz andan mal. No hace falta documento final de Davos 2006.

\section{2. "Una crisis global de empleo sin pre- cedentes"}

La cumbre sobre el desarrollo social (Copenhague 2005) declaró que los tres grandes problemas mundiales eran la pobreza, el crecimiento con desempleo, la insolidaridad y la atomización social. Diez años más tarde, Juan Somavia, director general de la Organización Internacional del Trabajo, afirma que el mundo afronta "una crisis global de empleo de enormes proporciones". De ahi la necesidad de que "el Foro Económico Mundial introduzca el tema de la creación de trabajo, el desarrollo de nuevas formas de ca- pacitación, el empleo global y la movilidad laboral en su agenda de 2006". Según Somavia, "la mitad de los trabajadores existentes - cerca de 1400 millones- vive con menos de dos dólares al día por persona, sin prestaciones ni seguridad o asistencia social. En segundo lugar, el desempleo, que actualmente afecta a 192 millones de personas, está en sus máximos niveles y continúa creciendo a un ritmo de 25 por ciento en los últimos diez años. Por último, la consecuente migración laboral se convierte con facilidad en fuente de tensiones [...] A pesar del fuerte crecimiento económico del 4.3 por ciento, en 2005, la economía mundial no está dando respuestas adecuadas [...], sería necesario crear cerca de 40 millones de trabajos cada año, en la próxima década, sólo para satisfacer la demanda del número creciente de trabajadores que buscan empleo" (El Confidencial, 26 de enero de 2006).

En Davos, varios ponentes hablaron de "La fiebre de Oriente" para resaltar el florecimiento de China e India. En efecto, China ha pasado a ser la cuarta potencia económica mundial, dada su tasa de crecimiento de casi un 10 por ciento (según cálculos conservadores), detrás de Estados Unidos, Japón y Alemania. "Es un súper petrolero a plena velocidad". También India presenta tasas de crecimiento similares. Algún empresario dinámico puede producir tractores compactos en China para exportarlos a Estados Unidos.

El foro de Davos subrayó la elevada tasa de crecimiento de China e India, pero sin mencionar la inseguridad económica y social de gran parte de sus trabajadores. Le Monde publicó, al final del año, un artículo iluminador: "China: $80 \%$ de las empresas privadas no ofrecen contrato a sus asalariados". Un informe oficial "revela que la inmensa mayoría de más de dos millones de empresas privadas chinas explotan a sus asalariados, condenados a trabajar sin contrato [...] Los derechos legales de los empleados son frecuentemente violados en más del 80 por ciento de las empresas privadas", declaró el diputado He Luli. Para el otro 20 por ciento de las empresas, que respeta la ley, los con- 
tratos son al menos de un año. "Los empresarios rechazan firmar contratos de larga duración para evitar las obligaciones legales", agrega el mismo diputado. "Incluso, algunos contratos establecen que el empresario no queda obligado en caso de enfermedad y aun de muerte de sus empleados, incluso si esto sucede en el lugar de trabajo". Este diputado dice que "es fundamental asegurar los intereses de los trabajadores".

China es, con toda razón, criticada por la ausencia de protección de sus empleados. El cinismo del Partido ha topado con la utopía. El derecho de huelga desapareció de la Constitución, en 1982, en razón de que el sistema político "ha erradicado los problemas entre el proletariado y los propietarios de las empresas". Un informe, preparado por la Confederación Internacional de Sindicatos $\mathrm{Li}$ bres, ha acusado al Partido Comunista Chino de haberse convertido en un "capitalismo de casino", caracterizado por el enriquecimiento de una minoría, gracias a la explotación de una masa de obreros, venidos del campo, mal pagados y sin ningún derecho. No disponen de medios para defender sus derechos, tanto más que el sindicato oficial -el único autorizado- defiende de forma sistemática la causa de los patronos. Por lo general, estas críticas, que representan el costo social del auge económico chino, provienen de organismos independientes, radicados en el exterior ( $L e$ Monde, 29 de diciembre de 2005).

En Davos se habló del problema social de China, por petición del empresariado occidental. "Para los expertos también es fundamental que los líderes empresariales tomen conciencia de la responsabilidad social que tienen y se impliquen claramente con causas como la reducción de la pobreza y de las enfermedades, el cuidado del medio ambiente, la educación y el cuidado de los derechos humanos de los ciudadanos. Por lo que se refiere a las economías emergentes, el tema estrella del Foro Económico Mundial de este año, los expertos reconocen que les preocupan los bajos costes de producción de Asia (25 por ciento de los encuestados), ya que eso reduce notablemente el precio final de los productos y la creciente influencia de las economías de esa zona (23\%). Esos son los principales motivos de que ese 23 por ciento de los encuestados reclame una mejora de las condiciones de trabajo de los trabajadores asiáticos y el respeto de sus derechos hurnanos fundamentales, lo que finalmente se podría traducir en un incremento de los costes de producción y del precio final de los productos $y$, por tanto, es una reducción de sus ventajas competitivas" ("Precio del petróleo y recursos naturales temores 2006, según encuesta", Terra, 27 de enero de 2006).

El foro social mundial de Bombay (2004) mostró "la India de los contrastes", puesto que presentó los efectos positivos y negativos de la economía de libre mercado. Si bien el problema de las castas, de los intocables y dalits, así como el papel secundario de la mujer, en esa cultura, son anteriores al advenimiento de la globalización, todo ello contribuye a que crezca la discriminación económica y social, es decir, los beneficiados y los perjudicados por el modelo neoliberal. "Aunque la clase política está convertida al liberalismo, porque muchos sectores dependen del Estado y no quieren enajenarse al electorado, poniendo en la calle a un mayor número de desempleados, fruto de las privatizaciones. Las leyes sociales, que ofrecen garantía a los asalariados, no gozan de mayor amplitud y las garantías jurídicas ignoran al sector informal, restringidas a la aristocracia obrera de las empresas y a los empleados de cuello blanco. Las estadísticas oficiales dicen que la pobreza se ha reducido en 'cifras relativas' $y$ que se ha elevado el PIB per cápita en los diez últimos años. Sin embargo, el país cuenta con el mayor número de pobres en el mundo (430 millones de personas viven con menos de un dólar, según el Banco Mundial). Además, sigue descendiendo su índice de desarrollo humano, de acuerdo al informe del PNUD; ha pasado del rango $94^{\circ}$ (sobre 130 países), en 1994 , al $124^{\circ}$, en 1995 , y al $127^{\circ}$, en 2003. Esta clasificación refleja el crecimiento de las desigualdades" (Entorno económico mundial, UCA Editores, 2005. pp. 296-297). 


\section{Alto precio del petróleo}

Es uno de los titulares que más aparece en la prensa, a finales de enero. De acuerdo con la encuesta, antes citada, el 34 por ciento de los expertos consultados cree que los mayores peligros de la globalización de la economía son "el aumento de precio del petróleo y el agotamiento de los recursos naturales". No se trata de repetir los debates y de las recomendaciones de la Cumbre de la tierra (Johannesburgo, 2002). El tema de las energías limpias y renovables era uno de los puntos a tratar en la reunión de Naciones Unidas, en su $60^{\circ}$ año de su fundación y uno de los tantos Objetivos del milenio que quedó en via muerta. Se trata simplemente de afirmar que asi piensan los expertos. "China y Estados Unidos dominarán la economía en 2006, según los expertos en Davos" (El País, 25 de enero de 2006). "Altos precios del petróleo. Estados Unidos, China e India seguirán siendo los grandes consumidores mundiales de crudo", agregó el experto Frenkel (asistente asiduo de Davos), quien advirtió también que "sin precios del petróleo tan altos como los actuales, las situaciones políticas de países como Rusia y Venezuela probablemente no serian las mismas" (El Confidencial, 26 de enero de 2006).

La "Demanda de crudo hará que los precios sigan altos". La advertencia se repite, "Los consumidores deberían acostumbrarse a precios elevados del petróleo en el mundo entero, debido a que la creciente demanda de crudo por parte de India, China y Estados Unidos, entre otros, hará que los precios tiren al alza y se mantengan altos". De acuerdo a Frenkel, "La capacidad de refinación también está agotada; así que los precios del crudo van a seguir altos". Los economistas del panel concluyeron que el gran tema de 2006 no será el del precio del "oro negro", sino el de si será posible mantener la demanda. "Vimos el pasado año que era posible tener una gran demanda [de crudo] y altos precios sin graves consecuencias económicas", aseguró Laura Tyson, decana de la London Bussines School.
Un crecimiento desbocado de China amenaza con provocar desequilibrios mundiales, a poco que el consumo interno aumente. Hasta ahora, los chinos, por miedo al futuro, han preferido ahorrar, dijo el vicepresidente de la Asamblea Nacional Popular, Chang Siwei. Tenemos que mejorar nuestro sistema de "seguridad social" para reducir el ahorro preventivo y "desarrollar el concepto del crédito", a fin de incentivar el consumo de los hogares. "Hasta ahora el crecimiento chino se ha apoyado totalmente en las exportaciones, es decir, en el consumo de sus socios extranjeros, como Estados Unidos y Europa, y en las inversiones". Ya es hora de que China cambie "su modelo para que pueda reposar más sobre el consumo", señaló Stephen Roach, de Morgan Stanley. Para el buen equilibrio de la economía mundial es necesario "más consumo y menos ahorro en China, y menos consumo y más ahorro en Estados Unidos", agregó Laura Tyson ( $E$ I Carabobeño, 25 de enero de 2006).

Esto significa que nuestra factura del petróleo volverá a sobrepasar los 900 millones de dólares, en 2006, y que no conviene adelantar predicciones de elevadas tasas de crecimiento, sino más bien de inflación. Más urgente sería que los ministerios de economía, medio ambiente y recursos naturales de Centroamérica, con el apoyo de expertos reconocidos, diseñaran un pacto o programa regional de energías limpias y renovables. Esta es la hora de ingenieros y ecologistas, es decir, de un tratado energético centroamericano.

\section{Las amenazas no económicas de Da- vos}

Bastantes expertos coinciden en que los fenómenos más dañinos para la economía son, precisamente, los no económicos, como "el trágico elenco de desastres naturales en 2005, el temor a la pandemia de la gripe aviar o la acción terrorista". Muchos de los informes de Davos vuelven sobre la amenaza de la gripe aviar, la cual representa un riesgo para todos. "El riesgo de que se produzca una pandemia entre humanos, si el virus de la gripe aviar muta hasta ser capaz de trans- 
mitirse entre personas, es el nuevo riesgo que aparece ya en cualquier conversación sobre el tema [...] Todavía no existe una vacuna contra ese virus y el suministro actual de antivirales es insuficiente para lidiar con el estallido de una pandemia global, según los expertos, que advierten además del tremendo coste económico - además de humanoque tendría en todos los sectores, inicialmente en el turístico, de transporte, servicios industriales, comercial o logístico" (El Confidencial, 26 de enero de 2006).

$\mathrm{Al}$ igual que Bush, la Secretaria de Estado Rice, desde Washington, por video-conferencia, abogó en Davos por combatir el terrorismo "en el marco de las leyes". "Todas las democracias deben enfrentarse a un muy difícil desafío [...] combatir el terrorismo en el marco de nuestras leyes, nuestros principios y nuestros valores. Rice añadió que Estados Unidos está convencido de que el pueblo palestino aún quiere la paz, pese a la victoria electoral del grupo radical Hámas", considerado por Washington un movimiento terrorista. Además, se declaró "extremadamente inquieta" ante el "evidente deseo" de Irán para poseer armas nucleares y reiteró que este país debe ser llevado ante el Consejo de Seguridad de Naciones Unidas para aplicar sanciones. Rice es la típica inventora del "círculo cuadrado", del cual nadie la saca, que impone sus leyes, sus principios, sus valores, pero que apaga la video-conferencia cuando otros toman la palabra. En la encuesta de la Gallup, la lucha contra el terrorismo ocupaba el quinto lugar.

¿Escuchó Rice la respuesta a su conferencia? Los líderes árabes pidieron respetar la victoria de Hámas. "Si la gente de Palestina votó a favor de Hámas, nosotros debemos respetar esa opción", dijo el presidente Afgano Hamid Karzai. Se trata de elecciones democráticas, llevadas a cabo sin incidentes violentos. "La realidad es que Hámas ha ganado. Ha sido escogido por la gente; entonces, nosotros deberiamos aceptar esa realidad", dijo Pervez Musharraf, presidente de Pakistán. Agregó que "esta realidad tiene que ser aceptada también por el gobierno israe- lî", aunque espera que Hámas evite el camino de la confrontación y acepte dialogar con Israel". Musharraf llamó a Israel a aceptar la existencia de Palestina y a Hámas a aceptar que "los israelíes son gente con familias $y$ niños como todos nosotros". La reina de Jordania opinó que "fue un voto de confianza para Hámas, pero también un voto contra las condiciones en las cuales han sido obligados a vivir los palestinos bajo la ocupación israelí. Esto es un ejemplo de que cuando la gente está frustrada y no tiene ninguna esperanza en su provenir, tiende a tomar la última opción posible". Sin embargo, expresó su confianza en que Hámas abandone su política de violencia y busque otras maneras para alcanzar la libertad de los palestinos (Notimex, 26 de enero de 2006). Rice no tiene el sabor del pueblo árabe palestino.

\section{Doha se cuela en el último minuto}

El fracaso de la cumbre de Hong Kong ha vuelto a generar nuevas tensiones en Davos, que no es el centro apropiado para discutir los problemas del comercio internacional. Incomprensiblemente, Peter Mandelson, representante de la Unión Europea en la cumbre de la Organización Mundial del Comercio, afirmó que "Europa no hará más concesiones en agricultura. No puedo suscribir un acuerdo en el que hacemos concesiones sobre agricultura y recibimos a cambio 'confetis'. En ese caso se trataría no de una negociación, sino de una capitulación". Esta afirmación lamentable es contraria a las promesas hechas en la cumbre de Doha (Qatar, 2001) y que en Hong Kong se relegaron al año 2013.

El canciller brasileño Celso Amorín utilizó el término, tantas veces repetida por el Premio Nobel Joseph Stiglitz, "hipocresía". En efecto, el canciller calificó de "hipócritas" algunas actuaciones. "No me impresionan" las palabras de Mandelson. Un proceso de negociaciones consiste en que lo que parece imposible al principio, sea posible al final". Amorin criticó con dureza ciertas actitudes "hipócritas" de los europeos, en materia de medio ambiente. "Dicen que quieren defender el medio ambiente, pero luego preten- 
den vendernos basura", en alusión a los neumáticos recauchutados europeos, cuya importación fue prohibida por Brasil. "Miren lo que es real y miren lo que es hipócrita". Amorín tampoco está muy de acuerdo con que, luego del fracaso de la de Hong Kong, se discutieran los temas del ciclo de Doha en una reunión informal, al margen de Davos, por no ser ni el tiempo ni el lugar apropiados (La Jornada, 27 de enero de 2006).

Después de todo, se llegó a fijar un "programa de trabajo" con 33 puntos controvertidos. Lastimosamente, quien haya seguido las promesas y las realidades de las cumbres de la Organización Mundial del Comercio sabe que en cinco años no se ha avanzado en los compromisos pactados $y$, por lo tanto, no pondrá su esperanza en estos "esbozos de un acuerdo". No obstante el acuerdo sobre un programa para las próximas reuniones comerciales, Davos concluyó sin haber conseguido un pacto. Los críticos de la ron- da comercial de Hong Kong aseguran que "los países industrializados fallaron en hacer concesiones sustanciales a los países en desarrollo y que sería mejor que las negociaciones colapsaran antes que generen un mal pacto. Pese a que se llegó a un consenso sobre un nuevo cronograma de trabajo, de todos modos salieron a la luz las diferencias entre los representantes comerciales que constituyen un desafío que deberá ser resuelto en el curso de los próximos meses" (BBCMundo.com, 30 de enero de 2006).

El ex presidente del Banco Mundial, James Wolfenshon, insistió en la justicia social y en la lucha contra la pobreza: "Estamos atravesando una etapa que no conocimos antes. El mundo está cambiando alrededor y los temas -economía, pobreza, justicia social y medio ambiente- son los temas claves que necesitamos tratar". Este es el documento final del foro económico de Davos de 2006. 